Manuscript version. Original article published in R. Frigg \& M. Hunter (Eds.), Beyond Mimesis and Convention, Boston Studies in the Philosophy of Science (pp. 71-96). Dordrecht: Springer (2010) and available at www.springerlink.com.

\title{
Models as make-believe
}

\author{
Adam Toon \\ Department of Philosophy \\ University of Bielefeld \\ P.O. Box 100131 \\ 33501 Bielefeld, Germany \\ adam.toon@uni-bielefeld.de
}

\begin{abstract}
In this paper I propose an account of representation for scientific models based on Kendall Walton's 'make-believe' theory of representation in art. I first set out the problem of scientific representation and respond to a recent argument due to Craig Callender and Jonathan Cohen, which aims to show that the problem may be easily dismissed. I then introduce my account of models as props in games of make-believe and show how it offers a solution to the problem. Finally, I demonstrate an important advantage my account has over other theories of scientific representation. All existing theories analyse scientific representation in terms of relations, such as similarity or denotation. By contrast, my account does not take representation in modelling to be essentially relational. For this reason, it can accommodate a group of models often ignored in discussions of scientific representation, namely models which are representational but which represent no actual object.
\end{abstract}




\section{Representation in modelling}

(i)

\section{The problem of scientific representation}

When we think of scientific models, perhaps the first things that come to mind are 'ball-and-stick' models of molecules or astronomical models of the solar system. Let us refer to such models as physical models, to indicate that they are actual, physical objects. Most philosophical work focuses not on physical models but on what I shall call theoretical modelling. Suppose we want to predict the behaviour of a bob bouncing on the end of a spring. To do so we might use Hooke's law to formulate the equation of motion for a simple harmonic oscillator, $m d^{2} x / d t^{2}=-k x$, where $m$ is the mass of the bob, $k$ is the 'spring constant' and $x$ is the displacement from the equilibrium position. In using this equation we make a number of assumptions: we take the bob to be a point mass $m$ subject only to a uniform gravitational field and a linear restoring force exerted by a massless frictionless spring with spring constant $k$ attached to a rigid surface. This is what Nancy Cartwright (1983) calls a 'prepared description' of the bouncing spring system. ${ }^{1}$ We realise that this description is false, but using it allows us to apply our equation of motion and calculate predictions for the bob's behaviour. This is an example of theoretical modelling: we model the bob as a simple harmonic oscillator. ${ }^{2}$

Many physical models represent some object or event in the world. Crick and Watson's famous model represents the DNA molecule. The astronomical models represent the solar system. An engineer's scale model might represent a bridge. We also represent the world through theoretical modelling. Of course, despite Cartwright's terminology, we cannot regard our 'prepared description' or equation of motion as straightforward descriptions of the bouncing spring; we realise that the bob is not a point mass and do not claim that it is. And yet we do represent the spring when we model it. Intuitively, we might say that we represent it as a simple harmonic oscillator. Put simply, the problem of representation for scientific models is to understand how such cases of representation work. In the case of theoretical modelling, this problem takes different forms depending on which view we adopt of the ontology of theoretical models. ${ }^{3}$ For example, according to Ronald Giere, a theoretical model like our model of the bouncing spring is not the prepared description and equation of motion that we

\footnotetext{
${ }^{1}$ Cartwright (1983).

${ }^{2}$ Note that I use the term 'theoretical' only to indicate that scientists do not construct a physical model of the system modelled, and not to imply that the model is derived from some existing theory, like Newtonian mechanics. Recent case studies suggest scientists must often go beyond existing theory to model a system; for example, see Morgan and Morrison (1999).

${ }^{3}$ For my own view of the ontology of theoretical modelling, see Toon (2010).
} 
write down, but some form of abstract entity that they define. Giere offers an indirect, two-stage, view of theoretical modelling: First, prepared descriptions and theoretical laws define abstract objects. Second, these objects represent (or, as Giere would put it, are used to represent) the system being modelled. If we adopt this view, then, understanding how we represent the bouncing spring is a matter of understanding the relation between the spring and the abstract simple harmonic oscillator defined by our prepared description and equation of motion.

To understand the problem of representation for models, it is helpful to look to another representational device: pictures. Like models, many pictures are representational, and some represent actual objects or events. Jacques-Louis David's Napoleon Crossing the Saint Bernard represents Napoleon. Constable's Salisbury Cathedral from the Meadows represents Salisbury Cathedral. The problem for theories of pictorial representation is to understand how they do this. In itself, Constable's painting is merely a collection of brushstrokes on a piece of canvas. And yet it depicts horses pulling a cart through a stream and the Cathedral beneath a rainbow. How does it do this? In virtue of what does Constable's painting represent the Cathedral? The problem of representation for scientific models may be presented in the same way. The reconstruction of Crick and Watson's original DNA model in the Science Museum is simply a collection of metal rods and plates held in place by clamps. And yet it represents the complex helical structure of the DNA molecule. How does it do this? In virtue of what does the model represent the molecule?

We have a name for the sort of representation pictures provide. We say that David's painting pictures or depicts Napoleon, and that Constable's landscape depicts Salisbury Cathedral. Of course, pictures represent in other ways too, apart from depiction. David's painting might be said to represent the glory of France, or Constable's 'the culmination of his numerous treatments of Salisbury Cathedral' ${ }^{4}$ Such is the vagueness of the term 'represent'. But it is one particular form of representation that pictures offer, namely depiction, which theories of pictorial representation seek to explain.

We lack a name for the way that models represent. If we say merely that models represent their objects then we are likely to be misled, for the word 'representation' is used in so many different ways. Crick and Watson's model might also be said to represent the greatest achievement of British science or Bohr's model a belief in the simplicity of the atomic realm. In analogy to pictorial representation, then, we might label the form of representation we are interested in modelrepresentation. Crick and Watson's model, we shall say, model-represents the DNA molecule and Bohr's model model-represents the atom.

\footnotetext{
${ }^{4}$ Salisbury Cathedral from the Meadows on www.nationalgallery.org.uk
} 
We must be careful here, however. The variety of scientific models is remarkable. What reason do we have for thinking that all of these models represent in the same way? Does Crick and Watson's model represent the DNA molecule in the same way as Bohr's model represents the atom, for example, or our model represents the bouncing spring? Might there not be many forms of modelrepresentation? Here the contrast with depiction is telling. The variety of things we call 'pictures' is also remarkable. It includes figurative paintings, Impressionist landscapes, political cartoons, children's drawings, stick figures and more. And yet despite their obvious differences, it is often thought that there is one form of representation that is common to all of these pictures, namely depiction. We lack the same intuitions for scientific models. Whether or not there is a form of representation common to both Crick and Watson's and Bohr's models, for example, would seem to be an open question that a theory of scientific representation must address.

We should not assume, then, that there is one form of representation common to all scientific models: there may be many different forms of model-representation. ${ }^{5}$ And we should also be careful not to assume that any of these forms of representation are unique to scientific models. Any, or even all, of the forms of model-representation that we identify may turn out to be employed by other representational devices, used either within or outside of science. Our theory of representation does not need to go on to say how, if at all, scientific models differ from these other representational devices, although this may be an interesting question in its own right.

The task of explaining how models represent is usually taken to be that of providing an account of a relation, between a model and that part of the world that it represents. For example, according to Craig Callender and Jonathan Cohen, the central question concerning representation for scientific models is 'what constitutes the representation relation between a model and the world?" ${ }^{6}$ The task for theories of depiction is often presented in the same way. A theory of depiction, it is often said, must tell us what the relation is between a picture and its subject, in virtue of which it depicts that subject. The difficulty with presenting the task in this way, of course, is that many pictures have no actual subject. And yet it seems that a picture of a unicorn is still depictive, even though there is no unicorn that it depicts. In Section III of this paper, I will argue that the same problem arises for scientific models: many models are representational, even though they represent no actual object. ${ }^{7}$ If we want to allow that such models are representational then we are faced with a dilemma: either we postulate some entity that they represent or we cease to think of model-representation as essentially relational.

\footnotetext{
${ }^{5}$ Versions of this point may be found in Frigg (2006), Hughes (1997) and Suárez (2003), although each draw rather different lessons from it.

${ }^{6}$ Callender and Cohen (2006), p68. See also Frigg (2006a) and Hughes (1997).

${ }^{7}$ This problem is also raised by Suárez (2003) and Callender and Cohen (2006). As we shall see in Section III, however, neither provide a solution.
} 
We ought, therefore, to refrain from presenting our task as that of giving an account of representation as a relation if we do not want to commit ourselves prematurely to the first route out of this dilemma.

\section{(ii) Misrepresentation}

Most models are inaccurate (or incorrect or unrealistic) in some way. Often this is deliberate. When we model the bouncing spring, for instance, we neglect the effects of air resistance. Sometimes, inaccuracy is unintentional: before building their famous double-helical model, for example, Crick and Watson constructed and rejected a number of different models of the DNA molecule. For our present purposes, the important point to notice is that inaccurate (or incorrect or unrealistic) models are still representations, and so must be accommodated by our theory of model-representation. Our simple harmonic oscillator model and a model that accounts for air resistance both represent the bouncing spring, and Crick and Watson's early efforts, like their final double-helical model, all represent the DNA molecule.

Many people share the intuition that an account of scientific representation should accommodate inaccurate, as well as accurate, models. For example, Mauricio Suárez writes that

we shall not require a theory of representation to mark or explain the distinction between accurate and inaccurate representation, or between a reliable and unreliable one, but merely between something that is a representation and something that is not. ${ }^{8}$

Some will disagree, however. Use of terms such as 'representation' or 'depiction' is often vague and subject to dispute. Are doodles really depictions? What about stick men? For some, 'representation' carries implications of realism, or at least empirical adequacy, when used with regard to scientific models. Although I do not understand the term in this way, I do not, of course, deny that the question of what makes one model more accurate or realistic than another is an important one. I claim only that this question need not be addressed by our theory of representation for models, which is concerned with the prior question of what makes something a model-representation. Once we understand how models represent, we will want to make further distinctions among models, distinguishing good from bad along various different dimensions. If someone wishes to reserve the term 'representation' for those models that fall only on the good side of one or more of these divides then we needn't quibble too much. The more important point is that our account of representation should provide us with the resources to make these distinctions amongst models.

\footnotetext{
${ }^{8}$ Suárez (2003), p226. See also Callender and Cohen (2006) and Frigg (2006a).
} 
The situation is similar with pictures. We often judge the realism of pictures, counting a Rembrandt more realistic than a cave painting or a Picasso. ${ }^{9}$ This raises the longstanding question of what makes one picture more realistic than another. Many theories of depiction suggest a natural answer to this question. For example, the view that pictures depict in virtue of similarity suggests a straightforward account of realism: the more a picture resembles its object, the more realistic it is. However, the question of what constitutes realism need not be addressed by a theory of depiction. Unrealistic pictures are still pictures; they still depict their objects. It is this which a theory of depiction must try to understand.

\section{(iii) Does the problem exist?}

The problem of representation in scientific modelling is now the focus of a burgeoning literature in the philosophy of science. Indeed, it is often referred to simply as 'the problem of scientific representation'. However, in a recent paper, Craig Callender and Jonathan Cohen have argued that this attention is unwarranted. In fact, they claim, 'there is no special problem about scientific representation'. ${ }^{10}$ In this section, and the one that follows, I shall attempt to show why Callender and Cohen are wrong. In doing so, I hope to clarify further the nature of the problem that faces us.

Callender and Cohen argue that we should approach the problem of scientific representation from a stance which they label as 'General Griceanism'. According to this view,

among the many sorts of representational entities (cars, cakes, equations, etc.), the representational status of most of them is derivative from the representational status of a privileged core of representations. [...] artistic, linguistic, representation and culinary representation $[\ldots]$ can be explained (in a unified way) as deriving from some more fundamental sorts of representations, which are typically taken to be mental states. ${ }^{11}$

A General Gricean account of representation therefore consists of two stages:

First, it explains the representational powers of derivative representations in terms of those of fundamental representations; second, it offers some other story to explain representation for the fundamental bearers of content. ${ }^{12}$

\footnotetext{
${ }^{9}$ Of course, this is not to claim that realism in modelling is the same as realism in painting.

${ }^{10}$ Callender and Cohen (2006)

${ }^{11}$ Ibid., p70

${ }^{12}$ Ibid., p71
} 
It is by adopting this General Gricean position that Callender and Cohen believe we may 'solve or dissolve the so-called 'problem of scientific representation": ${ }^{13}$

Our proposal $[\ldots]$ is that scientific representation is just another species of derivative representation to which the General Gricean account is straightforwardly applicable. This means that, while there may be outstanding issues about representation, there is no special problem about scientific representation. ${ }^{14}$

Callender and Cohen offer little argument in support of a General Gricean position. But let us, for the moment, suppose that we were to accept their proposal. What would this mean for our enquiry into model-representation? Presumably, the first stage would be to provide an account of how models represent in terms of some other, more fundamental form of representation such as mental or linguistic representation. Let us call such an account a derivative account of model-representation. A derivative account would attempt to show how the representational power of models derives from some other form of representation. By contrast, a non-derivative account would attempt to explain how models represent in non-representational terms. According to Callender and Cohen, providing a derivative account of model-representation 'amounts to a relatively trivial trade of one philosophical problem for another'. ${ }^{15}$ But if we could take this first step then we would have at least reduced the problem of explaining how models represent to the problem of explaining some other form of representation. And we might even feel at this stage that our work as philosophers of science was complete. The second step, of providing an account of the more fundamental form of representation, might be left to those working in the philosophy of mind or language.

However, immediately after they propose that we adopt the General Gricean approach to explain how models represent, Callender and Cohen expand on their claim in the following way:

\footnotetext{
[W]e propose that the varied representational vehicles used in scientific settings (models, equations, toothpick constructions, drawings, etc.) represent their targets (the behavior of ideal gases, quantum state evolutions, bridges) by virtue of the mental states of their makers/users. For example, the drawing represents the bridge because the maker of the drawing stipulates that it does, and intends to activate in his audience (consumers of the representational vehicle, including possibly himself) the belief that it does. ${ }^{16}$
}

This further claim comes as a surprise. Rather than being asked to take the first step in our General Gricean account of scientific representation, we are told that this step has already been taken. We do

\footnotetext{
${ }^{13}$ Ibid., p67

${ }^{14}$ Ibid., p77. Emphasis in original.

${ }^{15}$ Ibid., p73

${ }^{16}$ Ibid., p75
} 
not need to provide a derivative account of representation for models. In fact, this account has a very simple form: all that is required for a model to represent its target is that the user of the model stipulate that it does, and that he intend to bring about the belief that it does. Consequently, Callender and Cohen claim, 'scientific representation [...] is constituted in terms of a stipulation, together with an underlying theory of representation for mental states'. ${ }^{17}$ The representational relation between a drawing and a bridge, for example, is 'the product of mere stipulative fiat'. ${ }^{18}$ If this is correct, then there is indeed no special problem about scientific representation. Philosophers of science need no longer occupy themselves with finding even a derivative account of how models represent. It requires only an act of stipulation to bring about an instance of scientific representation. The remaining puzzles may be left to philosophers of mind.

What are we to make of this claim? Callender and Cohen seem to think that it follows directly from the General Gricean position. But it is difficult to see why this should be the case. It is one thing to claim that the representation relation between model and target exists only in virtue of some other, more fundamental, form of representation, such as mental representation; it is quite another thing to claim that an act of stipulation is sufficient to bring about this representational relation. In the first case, we claim merely that some form of derivative account of scientific representation may be found; in the second we commit ourselves to one particular, very simple, form that this account might take.

The parallel with depiction is helpful here. Suppose that we were to adopt the General Gricean position with regard to depiction. This would commit us to offering a derivative account that explained depiction in terms of some other, more fundamental form of representation. In fact, there are rather a lot of existing accounts that we could draw upon here. Consider the reconstruction of Plato's account of depiction offered by Alan Goldman,:

a picture represents an object if and only if (a) its artist successfully intends by marking a surface to create a visual experience that resembles that of the object, (b) such that the intention can be recovered from the experience, perhaps together with certain supplementary information, and (c) the object can be seen in the picture ${ }^{19}$

This account attempts to explain depiction in terms of, amongst other things, the intention of the artist to create a certain visual experience of an object. If successful, it will reduce the problem of depiction to some other problem (or problems) concerning mental representation. Or, to take another example, consider Kendall Walton's make-believe theory of depiction. ${ }^{20}$ I will be discussing Walton's views

\footnotetext{
${ }^{17}$ Ibid., p78

${ }^{18}$ Ibid., p75

${ }^{19}$ Goldman (2003), p194. Emphasis in original.

${ }^{20}$ See Chapter 8 of Walton (1990).
} 
more fully in Section II. For now, all that is important is that for Walton, depiction is explained in terms of particular acts of imaginings engaged in by the viewer of the picture: she imagines of her looking at the picture that it is an instance of looking at the object. Again, Walton's is a derivative account: it aims to explain depiction in terms of the representational capacities of mental states (in this case, imagination).

Either Goldman's or Walton's theories might constitute the first step in a General Gricean account of depiction. Yet the two accounts are very different, and the continuing debate over depiction suggests that taking either step would be far from trivial. Moreover, neither Goldman nor Walton's account parallels the derivative account of scientific representation offered by Callender and Cohen.

Presumably, such an account would claim that a picture depicts its subject if the painter stipulates that it does and intends to bring about the belief in the viewer that it does. Neither Goldman nor Walton take such an act of stipulation to be sufficient for depiction. And it is clear why they do not, for stipulation is plainly not sufficient for depiction. Suppose we took a blank canvas and stipulated that it represented Napoleon, and that that we intended to bring about the belief in others that this canvas represented Napoleon. And suppose further that this intention was recognised and our audience did believe that the canvas represented Napoleon. The blank canvas might, then, be said to represent Napoleon, in some sense, but it would not depict him.

Adopting the General Gricean position with regard to pictures, then, does not commit us to the view that stipulation is sufficient for depiction, but instead leaves open many different ways of explaining depiction in terms of other, more fundamental forms of representation. Similarly, we might adopt a General Gricean approach to models without taking stipulation to be sufficient for modelrepresentation. Just as there are many different candidates for a derivative account of depiction, so there might be many different derivative accounts of model-representation. Nevertheless, we might still ask whether the account that Callender and Cohen propose is successful. 
Is an act of stipulation sufficient for model-representation? To support their claim that it is, Callender and Cohen ask us to suppose that we were to pick up a salt shaker and stipulate to our dinner partner that it represents Madagascar. As long as our stipulation is understood, they point out,

when your dinner partner asks you what is your favorite geographical land mass, you can make the salt shaker salient with the reasonable intention that your doing so will activate in your audience the belief that Madagascar is your favorite geographical land mass ${ }^{21}$

According to Callender and Cohen, this shows that an act of stipulation, if properly recognised, is sufficient to establish an instance of scientific representation. Is this correct? Would we say that the salt shaker represents Madagascar? In some sense of the term 'represents' no doubt we would; again, the term is loose enough to support many different uses. But would we say that the salt shaker is a model-representation of Madagascar? Would it represent Madagascar in the same way that Crick and Watson's model represents the DNA molecule, for example, or Bohr's model represents the atom?

Let us again look to depiction. Perhaps the account of depiction that comes closest to claiming that stipulation is sufficient for depiction is Nelson Goodman's conventionalist account. According to Goodman, the relation between a picture and what it depicts is like that between a name and its referent; both refer to, stand for, or denote, their objects. Resemblance or similarity are neither necessary nor sufficient conditions for a picture to denote its object. In fact, 'almost anything may stand for almost anything else'.. ${ }^{22}$ One way to establish denotation, it seems, is by stipulation. If we stipulate that the blank canvas represents Napoleon then the canvas may be said to denote Napoleon. However, even Goodman does not take denotation to be sufficient for depiction. Instead, he recognises that his theory must account for the considerable intuitive differences between pictorial and non-pictorial representations. And he attempts to do so by presenting a number of formal criteria that are intended to distinguish pictorial symbol systems from non-pictorial ones, such as linguistic or diagrammatic symbol systems.

Both David's portrait and the name 'Napoleon' may be said to represent Napoleon. Perhaps both 'refer to' or 'denote' him. Similarly, both Crick and Watson's model and 'DNA molecule' might be said to represent or refer to or denote the DNA molecule. But any theory of depiction which counted

\footnotetext{
${ }^{21}$ Callender and Cohen (2006), p74

${ }^{22}$ Goodman (1976), p5
} 
the name 'Napoleon' a depiction of Napoleon would have failed to capture something important about the way that David's portrait represents Napoleon. Similarly, it seems that any theory of modelrepresentation that counted 'DNA molecule' a model-representation of the DNA molecule would have failed to capture something important about the way Crick and Watson's model represents the DNA molecule. It would have failed to characterise the particular form of representation that Crick and Watson's model provides. Our intuitions regarding scientific models are perhaps less clear-cut than our intuitions regarding pictures. But there still seem to be many differences between Crick and Watson's model and the name 'DNA molecule' that our theory must explain. The form of the name 'DNA molecule' is ultimately arbitrary, for example; any combination of letters could have done the job just as well. But the form of Crick and Watson's model was the subject of years of research and careful adjustment. Unlike the name 'DNA molecule', Crick and Watson's model seems to 'tell us' something about the DNA molecule, and we feel that in some way what it tells us can be right or wrong, accurate or inaccurate. Our theory of how models represent must account for these intuitions.

In the next section I will propose an account of scientific representation. First, however, let us sum up the problem that faces us. Many scientific models are representational. Some represent actual objects or events. The problem of scientific representation asks how they do this. Why does Crick and Watson's model represent the DNA molecule, or our model represent the bouncing spring? There may turn out to be many different forms of model-representation. Any, or even all, of these forms of representation may be employed by other representational devices, apart from scientific models. We want an account of each of these forms of model-representation. Theories of depiction aim to state conditions that are necessary and sufficient for something to be a depiction. Similarly, if possible, we want to provide a set of conditions that are both individually necessary and jointly sufficient to establish an instance of each form of model-representation that we identify. Our intuitions are less clear-cut in the case of models than for pictures. But our account should be able to distinguish models from merely denoting entities, like names or Callender and Cohen's salt shaker, as well as excluding non-representational entities, like ordinary chairs, tables or trees. ${ }^{23}$ And it should also accommodate inaccurate or incorrect models, as well as accurate or correct ones.

\footnotetext{
${ }^{23}$ Of course, in certain cases such objects may be representational. A chair might be used in a work of abstract art, for example, or a table used to represent a shelter in a play.
} 


\section{Models as make-believe}

\section{Walton's theory: props and games}

According to Walton, representations are props in games of make-believe. Suppose that some children play a game in the woods in which they imagine tree stumps to be bears. In Walton's terminology, in this game the tree stumps are props and the convention that the children establish by their agreement that stumps 'count as' bears is a principle of generation. Together, props and principles of generation make propositions fictional. To say that a proposition is fictional, on Walton's theory, is to say that there is a prescription to imagine it. (A fictional truth is simply the fact that a certain proposition is fictional.) Thus, given the rule that stumps 'count as' bears, if a participant in the game comes across a stump in a thicket, they are to imagine that there is a bear there; it is fictional that there is a bear there. ${ }^{24}$

What is fictional in a game of make-believe need not be the same as what is imagined. A stump which remains hidden under a pile of leaves still makes it fictional that a bear lurks there, even if this is never imagined by anyone playing the game. An oddly shaped stump might prompt one of the participants to imagine a wolf and not a bear, but the proposition that there is a wolf before them is only imagined, not fictional. Fictional truths therefore possess a certain kind of 'objectivity'; participants can be unaware of fictional truths and mistaken about them.

The stumps in the children's game are not representations, however. A representation, in Walton's sense, is not something that merely happens to be used as a prop; it is something of which it is the function to serve as such. ${ }^{25}$ Whether it is the function of a given object to serve as a prop depends upon social context. Walton's theory does not aim to analyse our ordinary use of the term 'representation', but to 'carve out a new category' that may be applied to what we might call works of fiction, including novels, paintings, sculptures, plays, films and musical works. ${ }^{26}$ Many other entities that we might normally call 'representations', such as most history books, newspaper articles, biographies or textbooks, Walton thinks, do not count as representations in his sense. ${ }^{27}$ The function of a biography of Napoleon, it seems, is not to prescribe imaginings about Napoleon, but to make certain claims about him. The biography does ask us to believe certain things of Napoleon, and it is

\footnotetext{
${ }^{24}$ These central features of the account are introduced in Section 1.5 of Walton (1990).

${ }^{25}$ See Section 1.7 of Walton (1990).

${ }^{26}$ Walton (1990), p2

${ }^{27}$ See Chapter 2 of Walton (1990).
} 
arguable that believing something requires us to imagine it. But there is no rule that we ought to believe what the biography says about Napoleon simply because it says it. On the other hand, Walton claims, there is a rule that we ought to imagine certain things of Napoleon when we read War and Peace, simply because the novel is written as it is. For this reason, the novel counts as a representation in Walton's sense.

Something is an object of a representation on Walton's theory if there are propositions about it which the representation makes fictional. ${ }^{28}$ Napoleon is an object of War and Peace, as is St. Petersburg. Salisbury Cathedral is an object of Constable's Salisbury Cathedral from the Meadows. Representation-as is a matter of what propositions about an object a representation makes fictional. War and Peace makes it fictional that Napoleon invaded Russia in 1812; it represents Napoleon as invading Russia in 1812. Sometimes, when we call something 'fictional' we do so to imply that it is false or even deceitful. To say a proposition is fictional in Walton's sense, however, is simply to say that there is a prescription to imagine it. This is perfectly compatible with truth. If a child screams when he comes across a stump in the woods, it will probably be fictional that he screams; it is both fictional and true that the child screams. Similarly, of course, it is true, as well as fictional in War and Peace, that Napoleon invaded Russia in 1812. In this respect, the novel corresponds to Napoleon. If a representation corresponds completely with its object then it matches it. But a work may represent something it does not match and match something it does not represent. It is fictional in The War of the Worlds that Martians attack London in the late nineteenth century. The novel represents London, but does not match it. Conversely, a portrait of John may match his twin brother David, but it represents John and not David.

As well as prescribing imaginings, the stumps in the children's game are also objects of those imaginings: the children imagine of the stumps that they are bears. This is not a necessary condition for something to count as a prop. The text of War and Peace may prescribe us to imagine many things of Napoleon, but we do not imagine the text of the novel itself to be Napoleon. Some works of fiction do prescribe imaginings about themselves, however. For example, we are to imagine that the first chapter of the novel Dracula is an excerpt from a journal. Walton calls these reflexive representations. ${ }^{29}$

The principle that wherever there is a stump, fictionally, there is a bear, was established by participants in the game by explicit stipulation. But Walton's theory does not demand that principles of generation be established in this way, nor that they be explicitly formulated. And indeed, many

\footnotetext{
${ }^{28}$ See Chapter 3 of Walton (1990).

${ }^{29}$ Ibid.., p 117
} 
implicit rules are likely to operate in the children's game: it may well be that if the stump in the thicket is taller than the stump under the leaves, then, fictionally, the bear in the thicket is taller than the bear hiding in the leaves. In the case of novels or paintings, principles of generation are difficult to specify explicitly, complex, and vary from case to case. The principles that apply to novels are conditional upon the text of the novel; those that apply to paintings or statues depend upon the distribution of paint on the canvas or on the form of the sculpted marble.

\section{Make-believe and model-representation}

With this outline of Walton's theory in place, let us now begin to apply it to scientific models. ${ }^{30}$ First, consider a physical model, such as a 1:1000 scale model of the Forth Road Bridge. I think we may regard this model as a representation in Walton's sense: the model functions as a prop in games of make-believe. These games are governed by certain principles of generation, appropriate for such models. One principle is that, if part of the model has a certain length, then we should imagine the corresponding part of the bridge to be a thousand times longer. Together, the model and principles of generation determine what users of the model are supposed to imagine; in Walton's terminology, they generate fictional truths. Some of these fictional truths are about the bridge itself. For example, if the model is a metre long, it will be fictional that the bridge is a thousand metres long. The bridge is therefore an object of the model; the model represents it as a thousand metres long. Since the Forth Road Bridge is in fact $1006 \mathrm{~m}$ long, the model represents the bridge but does not match it.

I propose that we regard all physical models in this way, as props in games of make-believe, which represent their objects by prescribing imaginings about them. The principles of generation by which models prescribe imaginings will vary from case to case. Were the bridge model built to carry out structural tests, for example, one principle of generation in effect may be that if the model is built from a certain material then it is fictional that the bridge is also built from that material. If, instead, the model were built for a museum display, however, this principle may not hold. Furthermore, not all physical models are scale models. The famous Phillips machine represents the workings of the macro-economy by the ebb and flow of coloured water in a hydraulic system. The principles guiding our imaginings when we use the Phillips machine will be very different from those that apply to the bridge model. One principle may be that if water is flowing through a certain pipe then, fictionally, taxes are being paid. Many physical models are reflexive representations, in Walton's sense: they

\footnotetext{
${ }^{30}$ The suggestion that Walton's theory may be applied in the context of scientific modelling is also made in Barberousse (2006), Barberousse and Ludwig (2000) and Frigg (2010). See below for a discussion of Frigg's views.
} 
prescribe imaginings about themselves. When we use the bridge model, for example, we not only imagine things of the bridge; we also imagine that the model itself is the bridge. Similarly, we imagine the balls of a ball-and-stick chemical model to be atoms, and the sticks to be bonds between them. Physical models need not be reflexive, however. When we use the Phillips machine, perhaps we do not imagine the flow of water itself to be the payment of taxes, but only that taxes are being paid.

Let us now turn to consider theoretical modelling. When we model the bouncing spring we write down an equation of motion $m d^{2} x / d t^{2}=-k x$, and a prepared description, which takes the bob to be a point mass $m$ subject to a linear restoring force, and so on. I believe these may be understood in the same way that Walton understands literary works of fiction. Consider the following passage from The War of the Worlds:

The dome of St. Paul's was dark against the sunrise, and injured, I saw for the first time, by a huge gaping cavity on its western side. ${ }^{31}$

Clearly, this is not a description of St Paul's Cathedral: when Wells wrote this he was not claiming that there really was a hole in the side of St Paul's. Nevertheless, on Walton's view, the passage still represents St Paul's; St Paul's is an object of The War of the Worlds. Usually, Walton thinks, when we read a linguistic work of fiction that uses proper names, we take ourselves to be prescribed to imagine things of the normal referents of those names. On this view, the above passage represents (the actual) St. Paul's, because it requires readers to imagine certain things of St Paul's, namely that it has a large hole in its dome. In Walton's terminology, the passage makes it fictional that St Paul's has a large hole in its dome.

I think we may use Walton's analysis to provide an account of our prepared description and equation of motion. We have seen that these are not straightforward descriptions of the bouncing spring. Nevertheless, I believe, they do represent the spring, in Walton's sense: they represent the spring by prescribing imaginings about it. When we put forward our prepared description and equation of motion, I think, those who are familiar with the process of theoretical modelling understand that they are to imagine certain things about the bouncing spring. Specifically, they are required to imagine that the bob is a point mass, that the spring exerts a linear restoring force, and so on. Unlike some physical models, our theoretical model is not a reflexive representation: we do not imagine that our description or equation are themselves a point mass or subject to a linear restoring force. Instead, our description and equation prescribe imaginings about the bouncing spring system. The bouncing spring

${ }^{31}$ Wells (2005), p170 
is an object of our model; our model represents it as a point mass, subject to a linear restoring force and a uniform gravitational field. Using Walton's terminology, we may say that our prepared description and equation of motion make it fictional that the bob is a point mass, that it is subject to a linear restoring force and so on.

My suggestion, then, is that models function as props in games of make-believe; model-representation is an instance of representation in Walton's sense. Tentatively, I claim that this notion of modelrepresentation applies to all physical and theoretical modelling. In physical modelling, the prop is a physical object, while in theoretical modelling, it is usually a prepared description and equation of motion. In some cases, the prop might be a diagram or picture. Just as for novels or paintings, the principles of generation governing the games in which these props function are complex and vary from case to case. In each case, however, the model represents in virtue of prescribing us to imagine things. We may formulate this account as follows:

$M$ is a model-representation if and only if $M$ functions as a prop in a game of make-believe (MM)

As we have seen, something is an object of a representation, on Walton's theory, if there are propositions about it which the model makes fictional. Taking this criterion together with the account (MM) allows us to state the conditions under which a model will represent some actual system:

$M$ model-represents $T$ if and only if $M$ functions as a prop in a game of make-believe in which propositions about $T$ are made fictional $\left(\mathrm{MM}_{1}\right)$

On the account I propose, then, where a model represents an actual system, it does so by prescribing imaginings about that system; in Walton's terminology, it makes propositions about the system fictional. However, the primary statement of the account remains that given in MM: a model $M$ is a model-representation, if and only if, if functions as a prop in a game of make-believe; it need not prescribe imaginings about any actual system. We shall see the importance of this feature of the account in Section III.

In the remainder of this paper, I will try to demonstrate the advantages of the account of representation I have proposed. First, however, it is important that this account is distinguished from another recent application of Walton's theory to scientific models. Frigg (2010) also suggests that the descriptions presented in theoretical modelling should be understood as props in Walton's sense. On his view, however, these descriptions prescribe us to imagine what he calls 'model systems', where these are to be understood as 
imagined physical systems, i.e. as hypothetical entities that, as a matter of fact, do not exist spatiotemporally but are nevertheless not purely mathematical or structural in that they would be physical things if they were real ${ }^{32}$

Frigg calls the means by which prepared descriptions and equations of motion give rise to these model systems 'p-representation'. For him, it is only this p-representation that is to be understood using Walton's theory. There is then a second representation relation, which he calls 't-representation', that exists between model systems and the world.

Frigg's account is therefore very different from that proposed in this paper. Like Giere, Frigg offers an indirect, two-stage, view of scientific modelling: prepared descriptions and equations of motion first give rise to model systems (p-representation) and these in turn represent the system being modelled (t-representation). By contrast, I do not take prepared descriptions and equations of motion to give rise to model systems. On my account, the prepared description and equation of motion that we write down when we model the bouncing spring, for example, do not prescribe us to imagine an 'imagined' or 'hypothetical' ideal oscillator. Rather, they prescribe us to imagine propositions about the actual bouncing spring: we imagine of the actual bob that it is a point mass and of the actual spring that it is massless, and so on. ${ }^{33}$ On my account, then, there are not two forms of representation relation, but only one, given by $\mathrm{MM}_{1}$ : the prepared description and equation of motion represent the bouncing spring directly, by prescribing imaginings about it.

Frigg's proposal is interesting, and its relationship to the account I have put forward merits further investigation. One reason I have for preferring my own application of Walton's theory has to do with questions regarding the nature of model systems. What exactly are 'imagined concrete systems' or 'hypothetical entities'? Like a number of other authors, Frigg compares model systems to fictional entities, like unicorns or Count Dracula. ${ }^{34}$ Of course, the nature of fictional entities, and in particular the question of whether such entities exist at all, is itself the subject of considerable controversy. Frigg acknowledges this, but claims that his account incurs no 'ontological commitments' since Walton's theory is antirealist with regard to fictional entities. ${ }^{35}$ And yet it is difficult to see how Frigg can take an antirealist stance on fictional entities, and thereby model systems, if these model systems are central to his account of theoretical modelling. If there are no model systems, what will do the trepresenting?

\footnotetext{
${ }^{32}$ Frigg (2010), p253.

${ }^{33}$ For more on the ontology of theoretical modelling, see Toon (2010).

${ }^{34}$ The suggestion that models might be understood as fictional entities is found in Godfrey-Smith (2006) and Frigg (2006b). Contessa (2010) follows this approach by developing his own 'dualist' account of fictional entities, while Thomson-Jones (2007) also explores versions of this view.

${ }^{35}$ Frigg (2010), p264.
} 
In Section I, I argued that we may accept Callender and Cohen's arguments in favour of adopting a derivative account of scientific representation, while rejecting their claim that stipulation is sufficient for scientific representation. The account I have proposed offers a derivative account: it explains the representational power of models in terms of the representational power of certain mental states, namely those of the imagination. For example, the bridge model represents the bridge in virtue of prescribing users to imagine that the bridge is a certain shape, length and so on. Unlike Callender and Cohen's stipulation view, however, my account is able to distinguish model-representation from cases of mere denotation or reference.

According to $\mathrm{MM}_{1}$, in order to be a model-representation of some object, a model must not only refer to that object; there must be an understanding amongst those who use the model that various imaginings are prescribed that depend upon the features of the model. This is absent in the case of Callender and Cohen's salt shaker. The act of stipulation they describe may establish that the salt shaker refers to Madagascar, but there is no understanding among the diners that they are to imagining anything about Madagascar, given the properties of the salt shaker. For the same reason, my account is also able to exclude proper names: no convention exists such that we are to imagine certain things of the DNA molecule depending upon the properties of the name 'DNA molecule', such as the number of letters it has or whether it is written in English or French.

Earlier, we observed that the form of a name like 'DNA molecule' is ultimately arbitrary, while that of a scientific model is often crucial to its representational function. Furthermore, we noted that scientific models seem to 'tell us' something about their objects, while names do not, and that what the model tells us can be right or wrong. We are now in a position to explain these differences. The reason that the properties of a model are important to its representational function, while those of names or Callender and Cohen's salt shaker are not, is that the imaginings the model prescribes about its object are conditional on those properties. What a model 'tells us' about its object is dependent on the content of those imaginings, and what it tells us is right or wrong depending on whether the propositions it asks us to imagine are true or false of that object.

Under certain circumstances, the salt shaker could become a model-representation of Madagascar. For example, we might imagine the shaker being used to indicate the location of Madagascar with respect to Africa (the dinner plate). In this case, the salt shaker (together with the dinner plate) would constitute a model-representation on my account: the salt shaker's properties prescribe us to imagine 
something about Madagascar, according to rules such as 'if the shaker is to the right of the plate, you are to imagine that Madagascar is to the east of Africa'. One way to establish this rule would be to declare it explicitly. As we have seen, however, principles of generation need not be stated explicitly. Many suggest themselves to us almost 'automatically'. Once we have explicitly specified that the salt shaker denote Madagascar and the plate denote Africa, it is almost inevitable that we will associate the relative positions of the salt shaker and the plate with the relative positions of Madagascar and Africa. The ease with which we understand such conventions, however, should not mislead us into neglecting their importance. No familiar principles of generation come to mind when we are told that the salt shaker represents Madagascar. (Its shape does not readily suggest taking it to be a scale model of Madagascar, for example.) In the absence of such principles, the salt shaker fails to modelrepresent Madagascar and merely refers to it; its properties are irrelevant to its representational function, and it can tell us nothing about Madagascar.

\section{(iv)}

\section{Make-believe, misrepresentation and realism}

In Section I, I argued that our theory of model-representation should be able to accommodate inaccurate (or incorrect or unrealistic) models as well as accurate ones. The account I have offered meets this criterion. According to $\mathrm{MM}_{1}$, a model represents an object if it makes propositions about that object fictional. Once again, recall that propositions can be fictional in Walton's sense and still be true. For example, our model of the bouncing spring makes it fictional that the bob has mass $m$ and that it is attached to a spring. However, it is not a condition for model-representation on my account that all, or even any, of the propositions a model makes fictional be true. For this reason, my account is able to accommodate inaccurate (or incorrect or unrealistic) models. Our model still represents the spring, even though much of what it asks us to imagine about it is false: the bob is not a point mass, the spring is not massless, and so on. Or again, like their final double-helical model, Crick and Watson's early models represent the DNA molecule because they prescribe us to imagine things about the molecule. It is simply that some, or even all, of what the early models ask us to imagine is false.

However, the accuracy, or realism, with which a model represents a system is often of considerable importance, of course. There are many questions that we might ask in this regard. Can we say anything general about the accuracy or realism of scientific models? If we can, how realistic are scientific models in general and in what respects? Are we justified in believing that scientific models are realistic representations of their objects? In this paper I am concerned not with these questions, 
but with the prior question of how scientific represent their target systems. As I have already noted, however, it would be desirable if our theory of model-representation provided us with a framework in which to address these questions about realism. The theory of model-representation I have proposed does provide such a framework, but this framework differs from that commonly employed.

On most accounts of scientific modelling, accuracy is judged in terms of some form of similarity or fit between a model and the world. For example, as we have seen, Giere takes theoretical models to be abstract objects defined by the prepared descriptions and equations of motion scientists write down when they model a system. The accuracy of a theoretical model is then a matter of the similarity between this abstract object and the system in certain respects and to certain degrees. In contrast to this indirect view of theoretical modelling, I propose a direct view. ${ }^{36}$ On my account, there is no abstract object (or fictional entity or any other kind of object) that satisfies scientists' prepared description and equation of motion; instead, the prepared description and equation represent the system directly, by prescribing imaginings about it. However, this account still provides us with a simple way of understanding the accuracy or realism of a theoretical model: put simply, a model is accurate in a certain respect if and only if what it prescribes us to imagine in that respect is true of the object it represents.

For example, consider our model of the bouncing spring. Whether this model is accurate is not a matter of whether some abstract ideal oscillator is similar to the bouncing spring. The model is accurate if what it prescribes us to imagine of the spring is true. For instance, the model prescribes us to imagine that the bob oscillates with a time period of $T=2 \pi \sqrt{m / k}$. The model is accurate in its prediction if, and only if, the bob does in fact oscillate with period $T=2 \pi \sqrt{m / k}$. On my account, then, the accuracy of a model is dependent upon the truth (or perhaps the approximate truth) of the propositions it prescribes us to imagine about the system it represents. This view may be applied to physical, as well as theoretical models; as we have seen, on my account, even physical models prescribe us to imagine propositions about their objects.

\section{(v) Models and works of fiction}

Many of entities to which Walton applies his theory, such as novels, painting and films, are central examples of works of fiction. If Walton does indeed offer the correct analysis of these works then, on my account, model-representation turns out to be an instance of a wider form of representation also instantiated by such works. Some will object to this comparison. Surely there are many differences

\footnotetext{
${ }^{36}$ Toon (2010)
} 
between our model of the bouncing spring and works of fiction such as War of the Worlds, or between an architect's scale model and a statue of Napoleon? Although I claim that models employ the same form of representation that Walton ascribes to works of fiction, I do not deny that there are many important differences between the two, as there are amongst works of fiction themselves. Similarly, to claim that some scientific drawings employ the same mode of representation as cartoons and Surrealist paintings, namely depiction, would not prevent us recognising the enormous differences between these different representations.

And, although there clearly are important differences between models and some works of fiction, I think it is less clear where to draw a line between them, if one can be drawn at all. It is clearly not correct to say that the imaginings models prescribe are generally true, or even approximately true, whereas those prescribed by works of fiction are not. As we have seen, even good models prescribe many false imaginings about their objects. Conversely, works of historical fiction often prescribe many true imaginings about actual characters and events, as do many portraits. Moreover, given that we know that something is a work of historical fiction or a portrait, it is arguable that we are entitled to expect the work to be accurate in these ways. The same considerations also show that we cannot draw the distinction in terms of whether or not the works aim at truth. One important function of many scientific models is that of providing us with predictions. But, again, this does not give a clear criterion for distinguishing models from works of fiction. On the one hand, it seems that some models are not used to provide predictions. Obvious examples here are the models we will consider in Part III, which do not represent an actual object. And on the other hand, it is arguable that some works of fiction offer predictions. One example here might be Orwell's Nineteen Eighty-Four. ${ }^{37}$

\section{Models without actual objects}

\section{The variety of models without actual objects}

As we noted in Section I(i), the problem of scientific representation is usually presented as that of giving an account of a relation between a model and some actual system, just as the problem of depiction is often said to be that of identifying a relation between a picture and its subject. We also observed, however, that many pictures seem to be depictive, even though they depict no actual

\footnotetext{
${ }^{37}$ Note also that the position I advocate is distinct from what Arthur Fine calls fictionalism. (Fine (1998). As Fine characterises it, fictionalism is an anti-realist position which argues that a scientific theory may be reliable without being true and without the entities it invokes existing. To classify a model as a representation in Walton's sense is to say nothing about the truth of the propositions the model prescribes or about the existence of the entities it invokes.
} 
subject. An illustrated edition of Dracula might contain a picture of Count Dracula, for example, his fangs dripping with blood. It seems that the picture represents or depicts Dracula, in a similar way to that in which a portrait like David's Napoleon Crossing the Saint Bernard depicts Napoleon. Of course, Count Dracula does not exist in the same way as Napoleon did. But if the painting represents Dracula, must he not exist in some sense? These problems also arise for discourse about fiction. If we say 'Dracula sucks blood' it seems we assert something true. And yet if Dracula does not exist, to what does the name 'Dracula' refer? Solutions to these problems fall into two camps.

Accommodationist theories grant fictional entities like Count Dracula some place in our ontology. Eliminativist theories attempt to show how fiction, and our discourse about it, may be understood without granting the existence of fictional entities. ${ }^{38}$

Many scientific models pose parallel problems. Obvious examples are models of entities we once thought to exist but now know not to. Nineteenth century physicists constructed mechanical models of the ether. Even if, as we now believe, the ether does not exist, these models still seem to be representational. Intuitively, we want to say that ether models represent something, even though we know there is no ether. Just as we seem to need Dracula to understand pictures of the Count, so we seem to need the ether to understand the physicists' models. The problem also arises for our discourse: just as we make statements that seem to refer to Dracula, so we might make statements that appear to refer to the ether, like 'the ether is at rest'.

The problems posed by models without actual objects is rarely recognised. Where it is recognised, it is always models of discredited entities like the ether or phlogiston that are offered as examples. In fact, however, problems with fictional entities arise for a much wider range of cases. Many of these are rather mundane. For example, suppose that engineers constructing a bridge invite architects to submit models of their proposed designs. Like the ether models, a model proposing an unsuccessful design would still seem to be representational, even if there is no actual bridge that it represents. Many scientific experiments create events which may never otherwise occur; a scientist might formulate a theoretical model of such an event even if funding runs out and the experiment never takes place. Or again, while using a ball-and-stick chemical model we might construct any number of models that represent configurations of atoms that do not exist.

In addition to examples such as these, there are clearly many cases of models that represent no particular actual object or event. We say that Bohr's model 'represents the hydrogen atom', for example, but presumably it does not represent any particular hydrogen atom (although it might be used to do so). In fact, it is arguable that most scientific models are of this form. In some cases, such

\footnotetext{
${ }^{38}$ The terms 'accommodationist' and 'eliminativist' are taken from Lamarque (2003).
} 
as that of the Bohr model, we might think that the model represents a type of entity or event. R.I.G. Hughes elects to 'assume without argument that our concept of denotation allows us to denote a type' and offers Bohr's model as an example. ${ }^{39}$ However, even allowing that we may make sense of the notion of a model representing a type, there are many models, or uses of models, that cannot be thought of in this way.

A comparison with pictures might once again be helpful. Many pictures would also appear to represent types. Examples might include encyclopaedia illustrations representing certain species of plants or the famous diagrams of man and woman on the plaque of the Pioneer spacecraft. But clearly not every picture that fails to represent a particular actual object may be thought of in this way. For example, Vermeer's The Milkmaid shows a woman pouring milk from a jug by a window. Even if Vermeer used a model when painting the work, there is no actual woman that the painting represents, nor does it represent a type of woman. Instead, the painting simply represents a particular fictional or 'imaginary' woman. There are numerous pictures of this sort. As Goodman puts it, 'the world of pictures teems with anonymous fictional persons, places, and things' ${ }^{40}$

Analogous cases exist in scientific modelling. Consider the Phillips machine. The machine could be used to represent some actual economy, such as that of Britain. Alternatively, perhaps it could be used to represent a type of economy. But we could also use the machine simply to represent a particular 'imaginary' or fictional economy. (We might begin by saying 'suppose there were an economy like this...'.) Or, to take another example, suppose that the 'prepared description' and equation of motion that we write down when we model the bouncing spring system were to appear instead in a textbook, written to instruct students on how to model a bouncing spring like ours. In this case, it seems there will be no actual system that the model represents, nor type of system. Instead, it represents an 'imaginary' or fictional bouncing spring that the student is to imagine encountering. ${ }^{41}$

Need an account of representation for scientific models accommodate those without actual objects? Callender and Cohen suggest we might 'bite the bullet and hold that, in cases where $x$ doesn't exist, agents don't succeed in representing $x$ but merely believe they are representing $x{ }^{42}$ As we have seen, this would be to exclude a considerable number of models from our account of representation. Moreover, in many of the cases we have considered, agents do not even believe that they are

\footnotetext{
${ }^{39}$ Hughes (1997), S330-1

${ }^{40}$ Goodman (1976), p26

${ }^{41}$ This example reminds us that the same prepared description and equation of motion may serve very different representational functions.

${ }^{42}$ Callender and Cohen (2006), p81 n11
} 
representing an actual object. Most importantly, however, I think it is simply wrong to deny that models without actual objects are representational.

A comparison with pictures is helpful. We take for granted that pictures without actual objects are representational. Of course, we recognise that when we say that The Milkmaid is a 'picture of a milkmaid' this does not license the inference that the milkmaid exists. However, even if she does not, the picture is undoubtedly still depictive. Indeed, our experience of the picture depends very little upon whether or not the milkmaid exists. We can still stand before the painting and admire her care and concentration in her task, just as we might look at David's portrait and admire Napoleon's bravery and determination. The same is true of models. Consider the architects' models discussed earlier, each showing proposals for a bridge design. Suppose that these models were all put on display after the bridge is built. If we were to inspect the models without knowing which was chosen, our experience of the unsuccessful models would be very similar to that of the successful one. Looking at these models, which might be built from balsa wood or paper or construction kit, and might be a metre or ten metres high, we could still recognise each as representing a bridge to be built across the river, and discuss whether that bridge is ugly or beautiful, flimsy or strong. Similarly, we realise that when we say a model 'represents the ether' we cannot conclude that there is an actual object that it represents. But the model is still representational. Indeed, the representational properties of ether models may have played an important role in allowing scientists to determine whether or not the ether exists.

In the next section, I will consider whether existing accounts of scientific representation can accommodate models without actual objects. First, however, it is important that our present problem is distinguished from another way in which scientific modelling is sometimes thought to give rise to fictional entities. This route to fictional entities arises from theoretical modelling of actual objects, like our model of the bouncing spring. When we model the spring we make assumptions that are true of no actual system: no actual pendulum is a point mass, no actual spring is massless, and so on. Recently, as we have already seen, a number of authors have suggested that our model of the bouncing spring is itself a fictional entity that satisfies these modelling assumptions. On this indirect view of theoretical modelling, our prepared description and equation of motion define a fictional idealised oscillator, and this, in turn, represents the bouncing spring. Theoretical models are themselves taken to be fictional entities.

I have argued against this view elsewhere. ${ }^{43}$ For now, we may simply note that the ontology of theoretical models themselves is not the problem that concerns us here. We want to know how our

${ }^{43}$ Toon (2010) 
account of representation can accommodate models without actual objects. It is possible for these two problems to become confused. Speaking loosely, we might say that our model of the bouncing spring 'represents' a point mass or a massless spring. Point masses and massless springs do not exist, of course, and it is tempting to label them as 'fictional entities'. Speaking more carefully, however, we should say that our model represents an actual pendulum bob as a point mass and it represents an actual spring as massless and frictionless. For this reason, it does not present the same problem as models like the ether model.

Moreover, even if we take theoretical models to be fictional entities, rather than linguistic entities or abstract objects, this does not solve the problem posed by models that represent no actual object. To see this, consider the theoretical model mentioned above, which represents an experimental event that never occurs. The problem we are faced with is that of explaining how it is that this model is representational, given that there is no actual object that it represents. Taking the model itself to be a fictional entity, rather than, say, a linguistic entity or abstract object, does not solve this problem. Or again, suppose that, before it was discovered not to exist, someone had produced a theoretical model of the ether that was thought to offer a highly simplified account of its behaviour. Even if we were to take the scientists' ether model to be a fictional entity, defined by whatever assumptions and equations they wrote down, we would still be left with the problem that this model, like a mechanical ether model, seems intuitively to represent the ether, even though there is no ether. ${ }^{44}$

\section{(ii) Existing accounts of scientific representation and models without actual objects}

Most existing accounts conceive of representation in modelling as a relation. This includes the similarity and isomorphism accounts criticised by Mauricio Suárez and Roman Frigg. ${ }^{45}$ It also includes Ronald Giere's more sophisticated similarity account, on which scientists use models to represent systems by forming 'theoretical hypotheses' detailing their similarities. ${ }^{46}$ Although Hughes' 'D.D.I. account' is not intended to provide necessary and sufficient conditions for representation, Hughes does endorse the maxim 'no representation without denotation'. ${ }^{47}$ Finally, as we have seen,

\footnotetext{
${ }^{44}$ Similarly, Frigg (2010) suggests that the problem of models without actual objects can be avoided simply by adopting his distinction between p-representation and t-representation. This alone does not seem sufficient to solve the problem, however: we still require an account of t-representation that can explain how some model systems (like the simplified ether model system) can be representational, without representing any actual object. ${ }^{45}$ Frigg (2006a), Suárez (1999) and (2003)

${ }^{46}$ Giere (2004). Giere allows there may be other ways in which models are used to represent, although does not specify any. See also Giere (1988) and (1999).

${ }^{47}$ Hughes (1997), S331. 'D.D.I.' stands for 'denotation, demonstration, and interpretation'. According to Hughes, these combine in the following way: 'Elements of the physical world are denoted by elements of the
} 
on Callender and Cohen's view, representation in modelling is a relation established by an act of stipulation connecting a model and its object. As they stand, none of these accounts can explain why models without actual objects are representational. An ether model cannot represent in virtue of its similarity or isomorphism to the ether if the ether does not exist, nor could a scientist list the model and ether's similarities in a theoretical hypothesis. The model also cannot denote or stand for the ether, and we cannot establish a representation relation between the model and the ether by stipulation.

If accounts that take representation in modelling to be a relation are to be applied to models without actual objects, then their proponents must posit some object for these models to represent. That is, they must adopt an accommodationist stance on fictional entities. Whether this is thought to be problematic would depend upon which accommodationist view was adopted and how palatable its ontological commitments were taken to be. However, it would be a mistake to assume that the problem disappears once we posit fictional entities. In fact, questions would remain for each of the accounts. For example, would the objects posited to serve as fictional entities have the right properties to enter into relations of similarity or isomorphism with models? The claim that models may denote fictional entities, just as they denote actual entities, would also be open to debate.

Fictional objects are dependent on representations for their existence in a way that actual objects are not; the relation between a representation and a fictional object, if there are any, would therefore appear very different from that between a representation and an actual object. ${ }^{48}$ Finally, could we say that the ether model is representational because it was stipulated that it represent a fictional ether? If any stipulation occurred it was surely that the model represent the real ether.

The only account of scientific representation that attempts to accommodate models that represent no actual object is Mauricio Suárez's 'inferential conception'. On this view, a representational source A represents some target B 'only if (i) the representational force of A points towards B and (ii) A allows competent and informed agents to draw specific inferences regarding B. ${ }^{49}$ At first sight, then, it seems that the inferential conception also regards representation as a relation. However, Suárez argues that this account can accommodate what he calls 'fictional representation, that is, representations of nonexisting entities', and in fact, he claims that on his account 'there is absolutely no difference in kind between fictional and real-object representation - other than the existence or otherwise of the target'. ${ }^{50}$

model; the model possesses an internal dynamic that allows us to demonstrate theoretical conclusions; these in turn need to be interpreted if we are to make predictions' (Hughes (1997), S325).

${ }^{48}$ Walton (1990), p127

${ }^{49}$ Suárez (2004), p773

${ }^{50}$ Ibid., p770 
How is this supposed to work? Consider an ether model. Even though the ether does not exist, perhaps there is a sense in which we might say that the model possesses a representational force 'towards the ether' just as, for example, a model of the Forth Road Bridge possesses a representational force towards the bridge. The ether model is rather like a description such as 'the only inhabitant of London': both purportedly pick out an object; they simply fail to do so because that object does not exist. However, it is not clear that we may say this in all cases. For example, consider the case discussed above, in which the Phillips machine is used to represent an 'imaginary' economy. Unlike the creator of an ether model, the user of the Phillips machine does not attempt, but fail, to represent an actual object. When used in this way, the Phillips machine does not purport to represent any actual object. As a result, it is difficult to make sense of the idea that this model possesses a representation force, even a thwarted one, presuming that representational force always points towards actual objects or events. Of course, we might attempt to get round this problem by granting the existence of fictional entities and allowing that representational force may point to them too. But then the claim that there is no difference between representation of fictional entities and of actual ones would require further argument for, as mentioned already, the relation between a representation and a fictional object and the relation between a representation and an actual object would appear to be rather different.

\section{(iii) Models as make-believe and models without actual objects}

Unlike similarity and isomorphism accounts, Hughes' D.D.I. account or Callender and Cohen's stipulation view, the account of models I set out above (MM) does not take representation in modelling to be a relation. It is therefore able to accommodate models that represent no actual object without postulating some object for them to represent. Something is a model-representation if it has the function of serving as a prop in games of make-believe; it is not a necessary condition for modelrepresentation that there be any object that the model prescribe imaginings about. Ether models, or the textbook model of a bouncing spring or the model for an experiment that does not take place, are all representational because they function as a prop in a game of make-believe; all of them are taken to prescribe imaginings. They can still fulfil this role even if there is no object that they prescribe imaginings about.

Of course, other accounts of representation in art and elsewhere, apart from Walton's, acknowledge that it may fail to be a relation in certain cases. For example, although Hughes bases his D.D.I. account on Goodman's theory of representation, Goodman does not endorse Hughes' maxim 'no 
representation without denotation'. Instead, Goodman allows that denotation may fail in certain cases and considers it necessary only that representations are 'ostensibly provided with denotata' ${ }^{51}$ For example, we might say that 'the only inhabitant of London' is ostensibly provided with a denotatum; it simply fails to denote because no one happens to satisfy the description. Walton's position is more radical. On his account, the notion of having an object is not central to representation in any way. He asks us to imagine a society of people who make pictures, say, 'of people' or 'of trees', but never pictures that depict actual people or trees. Drawing or painting a person is thought of as creating or making an imaginary person and not representing any real person. And yet, Walton argues, these pictures would still be representational. Unlike Suárez's inferential conception, then, my account can accommodate cases in which there is not even attempted reference to any object, like Phillips machine being used to represent an 'imaginary' economy.

Problems concerning fictional entities have not been entirely dispelled, however. For in addition to prescribing many unproblematic imaginings, such as that the speed of light is constant or that electromagnetic waves are transverse, intuitively it seems that an ether model will also prescribe imaginings 'about the ether'. For example, it may ask us to imagine that the ether is at rest. Once again, then, we meet the problem of fictional entities, this time for imagination: how are we to understand the contents of imaginings that appear directed towards fictional entities like the ether? This is certainly a problem, but it is not one that a theory of representation for scientific models need address. Instead, it is a general problem that faces all theories of intentionality. And it is a problem that will exist whatever account of representation we adopt for scientific models; even those who hold similarity or isomorphism accounts will concede that we often appear to imagine things of the ether. ${ }^{52}$ The same is true of the problem posed by discourse apparently referring to fictional entities, like 'the ether is at rest' or 'the bridge is stable' (said in reference to a failed bridge model). This too is a general problem that exists whatever our account of scientific representation and is the subject of longstanding debate.

\footnotetext{
${ }^{51}$ Goodman (1976), p228. Emphasis in original.

${ }^{52}$ Callender and Cohen also attempt to defer the problem posed by models without actual objects, observing that 'the worry arises for all species of representation - not just scientific representation - and there is no reason to suspect that whatever ultimately explains representations of unicorns and golden mountains won't work for representation of phlogiston and the ether' (Callender and Cohen (2006), p81). There is an important difference between Callender and Cohen's deferral strategy and my own, however. Callender and Cohen simply express a hope that a solution to the problem for other forms of representation may be applied to scientific models. They tentatively suggest a 'Humean strategy', which provides a relational theory for 'atomic' representations and explains representations without actual objects as constructed as 'compounds' of other representations. But they do not show whether this can be applied to scientific models, nor whether their account would remain intact if it were. This amounts simply to deferring the problem for scientific representation itself. By contrast, my own account reduces the problem of understanding models without actual objects to the more general problem of understanding imaginings about fictional entities.
} 


\section{Conclusion}

Scientific models are props in games of make-believe, which represent their objects by prescribing imaginings about them. Analysing models in this way allows us to accommodate models which represent their objects inaccurately, while showing how models differ from merely denoting entities, like Callender and Cohen's salt shaker. Since this account does not take representation in modelling to be essentially relational, it is also able to accommodate an important group of models that have been largely ignored by recent philosophical work on modelling, namely those that are representational, but represent no actual object.

\section{Acknowledgements}

This paper is based on a talk delivered at the 'Beyond Mimesis and Nominalism' conference held at LSE in June 2006. Parts of the paper were also presented at the Philosophy Workshop in Cambridge in June 2006, the CMM Graduate Conference held in Leeds in June 2007, and the 'Scientific Models: Semantics and Ontology' workshop, held in Barcelona in July 2007. I would like to thank participants at all of these events. Thanks also to Nancy Cartwright, Stacie Friend, Manuel GarciaCarpintero, Ronald Giere, Mary Leng, Mauricio Suárez, Paul Teller, Martin Thomson-Jones and Kendall Walton for helpful discussion and correspondence, and to Roman Frigg and two anonymous referees for comments on drafts of this paper. Finally, I would like to thank my $\mathrm{PhD}$ supervisor Martin Kusch, and my advisor, the late Peter Lipton. Research for this paper was supported by The Arts and Humanties Research Council, The Darwin Trust of Edinburgh and The Rausing Fund for History and Philosophy of Science. I am very grateful to all of these institutions for their support. 


\section{References}

Barberousse (2006) 'Images of Theoretical Models' Unpublished paper delivered at A.P.A. MiniConference on Scientific Images, March 2006.

Barberousse, A. and Ludwig, P. (2000) 'Les modèles comme fictions', Philosophie 68: 16-43.

Callender, C. and Cohen, J. (2006) 'There Is No Special Problem About Scientific Representation', Theoria 55: 7-25.

Cartwright, N. (1983) How the Laws of Physics Lie. Oxford: Oxford University Press.

Contessa, G. (2010) 'Scientific Models as Fictional Objects', Synthese 172: 215-229.

Fine, A. (1998) 'Fictionalism', in E. Craig (ed.), Routledge Encyclopedia of Philosophy. (Retrieved December 05, 2007, from http://www.rep.routledge.com/article/Q035)

Frigg, R. (2006a) 'Scientific Representation and the Semantic View of Theories', Theoria 55: 49-65.

- (2006b) 'Scientific Models' in Sarkar, S. and Pfeifer, J. eds. The Philosophy of Science: An Encyclopedia, with Stephan Hartmann. 740-749.

(2010) 'Models and fiction', Synthese 172: 251-268.

Giere, R. (1988) Explaining Science. Chicago: Chicago University Press.

- (1999) Science Without Laws. Chicago: Chicago University Press.

- (2004) 'How Models are Used to Represent Reality', Philosophy of Science 71: S742-752.

Godfrey-Smith, P. (2006) 'The strategy of model-based science', Biology and Philosophy 21: 725740.

Goldman, A. (2003) 'Representation in Art' in Levinson, J. (ed.), (2003) The Oxford Handbook of Aesthetics. Oxford: Oxford University Press. 192-210.

Goodman, N. (1976) Languages of Art. Indianapolis: Hackett.

Hughes, R.I.G. (1997) ‘Models and Representation', Philosophy of Science 64: S325-336. 
Lamarque, P. (2003) 'Fiction' in Levinson (2003). 377-391.

Morgan, M. and Morrison, M. (1999) Models as Mediators. Cambridge: Cambridge University Press.

Suárez, M. (1999) 'Theories, Models, and Representations' in Magnani, L., Nersessian, N.J., and Thagard, P. (eds.) (1999) Model-Based Reasoning and Scientific Discovery. New York: Kluwer/Plenum. 75-83.

- (2003) 'Scientific representation: against similarity and isomorphism', International Studies in the Philosophy of Science 17: 225-244.

- (2004) 'An Inferential Conception of Scientific Representation', Philosophy of Science 71: S767-779.

Thomson-Jones, M. (2007) 'Missing Systems and the Face Value Practice' (Retrievable from http://philsci-archive.pitt.edu/archive/00003519)

(2010) 'Missing Systems and the Face Value Practice' Synthese 172: 283-299

Toon, A. (2010) 'The Ontology of Theoretical Modelling: Models as Make-Believe' Synthese 172: 301-315

Walton, K. (1990) Mimesis as Make-Believe. Cambridge: Harvard University Press.

Wells, H.G. (2005) The War of the Worlds. London: Penguin (1st ed. 1898) 